\title{
The Efficacy of Re-Entry Policy and its Implications on the Zambian Education System
}

\author{
Dr. Martin Banda*, Mable Sitali Nowanga ${ }^{1}$ \\ *Department of Educational Psychology and Sociology \\ Kwame Nkrumah University, Kabwe-Zambia \\ ${ }^{I}$ Department of Educational Administration and Policy Studies \\ Kwame Nkrumah University, Kabwe-Zambia
}

*Corresponding Author: Martin Banda, Department of Educational Psychology and Sociology Kwame Nkrumah University, Kabwe-Zambia

\begin{abstract}
The main objectives of the study were to establish the effectiveness of the re-entry policy of girls who fall pregnant, investigate if this Policy is in line with the aims of Secondary School education and the general aims and objectives of education in Zambia and to find out what can be done to make the policy relevant.
\end{abstract}

This study is significant as it brings to fore the effectiveness of the re-entry policy of girls who fall pregnant in Secondary Schools with the major focus on how they behave when re-admitted. It is also relevant as it develops recommendations that may be useful in the contest to increase girl child retention and best approaches in the execution of this policy in the country and elsewhere where the similar policy had been implemented.

The study employed qualitative and quantitative research methods to focus on the meaning that girl pupils make of their lives, their experiences, and their environment. The main research instruments were a selfadministered questionnaire and face to face interview.

The findings show that the re-entry policy was effective in terms of retention of girls who fall pregnant in aspects of re-admission, progression, completion though there had been challenges in terms performance, high achievement and behaviour. The study concluded that although the policy was effective in areas of readmitting girls and ensuring their completion of education a lot needed to be done in terms of moral uprightness and excellence among young mothers especially on the aspect of deterring others from becoming pregnant and behaving well in school when they re-enter. The study further concluded that the girls who fell pregnant might not need to join the conventional schools but join the adult education structures of education. Recommendations included, the need for increased sensitisation to effectively deal with misconceptions that the Re-entry policy promotes promiscuity among young girls by promoting the benefits of the policy on both the individual and improving ability of girls to progress to higher levels of education, make available guidance and counselling services to girls on life matters; schools to take the policy seriously, ensure that learners have a strong relationship with at least one adult in the school, , improve the communication between parents and schools, increased supervision in school and more class room discipline, teacher reorientation and training to handle issues of pregnancy and re-entry policy and adult education, empowering of vulnerable families through community initiatives, as well as additional supports and adult advocates.

.Keywords: Effectiveness, Education, Norms, Re-entry policy, senior secondary.

\section{BACKGROUND OF THE STUDY}

Zambia's education progression has been embedded in a policy document of 1996 namely "Educating our Future". The key thrusts for the Zambia Education Policy and implementation are Access and Participation, Quality and Relevance, Efficiency, Effectiveness and Equity. In the Ministry of Education teaching and learning services are provided through Provincial Education offices and District Education Boards at district level based on the Ministry of Education vision and mission.

MOE ( 1996) in the mission statement reads in part, “... is to guide the provision of education for all Zambians so that they are able to pursue knowledge and skills, manifest excellence in performance and moral uprightness..." Through schools, particular skills, knowledge, positive judgement and well 
developed wisdom are developed so that individuals going through the educational process will become in the future useful and active members of society. Besides this aim, schools are seen as strong agents of social change in the communities where they are found and established.

In line with the MOE thrust and mission, and numerous International Documents including the 1948 Universal Declaration of Human Rights, Social Cultural Rights, the Elimination of All Forms of Discrimination against Women and fifty-fifty enrolment policy among others. As a fulfilment of the above-mentioned Documents, Zambia alongside other stakeholders soon after the 1995 World Conference on Women launched a girl-child campaign called Programme for Advancement of Girl Education (PAGE) whose aim was to create girl friendly school and provide school requisites such as pens, books, pencils, and paying school fees. The government also introduced different cut-off points for boys and girls of which the cut-off point for girls is lower than that of boys. In addition, in 1997 the government went further to introduce the re-entry policy to allow girl-child who became pregnant to go back to school after six months of her delivery.

However, in the recent past since the establishment of the above-mentioned initiatives government has been concerned towards improving girls' access, retention and performance. Though, the gender disparities are still wide. In the document produced by Faweza in 2010 indicates that there are more barriers for girls to surmount in order to access education. Some of the barriers include; school location, long walking distances that tire girls out and expose them to sexual abuse. This has resulted in a number of girls dropping out of schools or getting pregnant while still in school due to pressure of looking for money to buy few necessities especially for those from less well-off parents.

On another front, research regarding the effectiveness of the re-entry policy for girls who fall pregnant and the moral implication of the policy has apparently not attracted much attention and this has made information on the above-mentioned issue scanty, yet the availability of such information is vital to progressive policy formulation within the education sector.

\subsection{Statement of the Problem}

In the recent past there has been significant debate both in the media and public places on whether the MOE's re-entry policy for girls who fall pregnant should continue or not. It is indisputable that Zambia's school re-entry policy was well intended especially in a Zambian society which has been characterised by inequality among men and women. The re-entry policy as a measure and recognition of the importance of addressing gender inequalities in national development and the need to narrow the gender gap in education which was introduced on October 13, 1997 has scored a number of successes as some girls have gone back to school and successfully completed their secondary education, though some, older than the age they initially would have done so.

However, it is hardly exaggeration of truth to state that the policy has not fully achieved its objectives in the 19 years that it has been in existence. This is in accordance with statistics of beneficiaries and also missing information on how those readmitted behave. According to Zambia Daily Mail (September 26, 2012), the Minister of General Education at that time Dr. John Phiri told Parliament on $25^{\text {th }}$ September, 2012 that 12,617 girls were re-admitted in school under the school re-entry policy after falling pregnant between 2009 and 2011. During the same statement, the minister informed the house that there is need to do a more meaningful research into the re-entry policy which came into force in 1997 to establish whether it is working and if not to identify the impediments.

Three years later after the Ministers' call to do a meaningful research into the re-entry policy to establish whether it is working effectively, the then Kabwe Deputy Mayor, McDonald Mwamba, was reported calling for the abolishment of the policy given its alleged failure to improve the advancement of girls' education. The civic leader pointed out that Government should revisit the re-entry policy for girls, arguing that the policy promotes immorality among children and causes more harm than good in society (Zambia Daily Mail July 3, 2015).

In addition, a section of parents, teachers, traders and many other people in Kaoma Township share the deputy mayor's concerns on the re-entry policy and feel that the policy is encouraging girls to fall pregnant knowing very well that they will still go back to school upon delivery. This abuse of the re- 
entry policy also extends to making it difficult for schools to inculcate discipline and morals in other learners and subsequently making the learning process difficult.

In light of the above, this study sought to establish the effectiveness of the re-entry policy of the Ministry of Education to re-admit the girls that fall pregnant into schools in selected schools for the past (3) years up to December, 2015 with the focus of Kaoma District which had alarming statistics.

\subsection{Purpose of the Study}

The purpose of this study was to establish the effectiveness of the re-entry policy of the Ministry of Education to re-admit the girls into schools that fall pregnant in Kaoma urban and generate possible alternatives towards making the policy meaningful.

\subsection{Objectives of the Study}

The objectives of the study were to:

a) Examine the effectiveness of the re-entry policy in secondary schools in Lusaka urban.

b) Investigate the views of pupils on the re-entry policy.

c) Assess the behaviour of young mothers when they re-enter school in Lusaka urban.

\subsection{Research Questions}

The study was guided by the following questions:

a) How effective is the re-entry policy in secondary schools in Lusaka urban?

b) How do pupils view the re-entry policy?

c) How do young mothers behave when they re-enter school in Lusaka urban?

\section{Notes ON RE-EnTRy Policy Literature}

Education is a basic human right for all children. This was recognised 68 years ago in the Universal Declaration of Human Rights, acknowledged and agreed to by many governments across the world. However, in Africa millions of children, particularly girls, are still denied the right to education and are unable to access the knowledge, skills and capabilities necessary to take an empowered and equal role in society.

It is for this reason that the education system in Zambia has undergone some changes which have roots in the pre-colonial era. However, the passion that many Zambians had for education, as evident from the long distance they had to cover in order to get to school, made the government, after independence, to make strategic changes to the education sector. One of the major issues that the new government was faced with after independence was to make places in school to no longer being limited to the privileged few but to all children. As a consequence, many people, young and old yearned to learn and be in school. Carmody (1999:100) acknowledges that, "education should be compulsory, free and not in any way be subject to the individual's creed, colour or sex." Thus, all those rules and regulations that prevented some children from accessing education were abolished. The government aimed at providing primary education to all children. It was no longer seen as a privilege to be educated but as each child's right.

More than ever, the right to education which is entrenched in international human rights treaties, and commitments to girls' education have been made in a number of international and regional agreements and frameworks, ratified by the majority of African states. Many African states have introduced national policies to enact their commitments to girls' education under these international and regional frameworks. Policies aiming for the achievement of universal primary education and the removal of school fees are common across the continent. In some cases girls' education has been explicitly addressed in separate policies such as Kenya's Gender Policy in Education and Liberia's National Policy on Girls' Education.

This call which came amidst the problem of teenage pregnancy among schoolgirls is a major concern in many countries and a constraint in the elimination of gender disparities in education. Furthermore, 
on a continent where the adage when you educate a woman you educate a nation holds so true, the repercussions of girls dropping out of school due to pregnancy cannot be underestimated. To further this several studies conducted in Africa have shown that an investment in girls' education is an investment in the family, community and nation, the centrality of women's contribution to national development cannot also be taken too lightly. It improves overall quality of life (MOE 1996, Adetunde \& Akensina 2008).

As such the policy initiative to allow girls who fall pregnant to be readmitted as a way to promote girls' education which is grounded in the outcomes of the Beijing Conference of 1995, a conference at which the Women's Movement drew up its own priorities and action plan. The conference demanded that girls who dropped out of school because of pregnancy should be readmitted. Despite the existence of such policies, Plan's research shows public awareness of government policies and initiatives around girls' education remains very low. In Ghana only $30 \%$ of parents surveyed were aware of government efforts to support girls' secondary education, whilst in Liberia only $51 \%$ of parents knew of the government's education policies and initiatives related to girls. This inevitably impacts on the efficacy of policies, particularly where entrenched community.

Literature shows that after the Beijing Conference in 1995, and when the Forum for African Women Educationalists of Zambia (FAWEZA 2004) was established on 8 March 1996, it added its voice to the call for policy change concerning girls who got pregnant. And in September 1997, a conference on girls' education was held at Mulungushi International Conference Centre, Lusaka, at which the then Minister of Education, Dr. Syamukayumbu Syamujaye, announced that schoolgirls who became pregnant would no longer be expelled, and that those that had been expelled in 1997 should be allowed to return to school.

In assessing the effectiveness and need for the policy to re-admit girls that fall pregnant into schools which is supported by several scholars who have pointed out that the education of this category is particularly associated with significant reductions in infant mortality and morbidity, improvement in family nutrition and health, lowering of fertility rates, improved chances of children's education, and increased opportunities for income earning in both wage and non-wage sectors (Kelly 1999). The Demographic and Health Survey (2014) also revealed that the social benefits associated with secondary education of girls included lower fertility rates, later age of first marriage, greatly reduced infant and child mortality, reduced incidence of child malnutrition. Thus, the concern about improving the educational rights of girls who become pregnant is based in part on the knowledge that this will affect the fate of their children and future generations.

However, for some time now, it has been noted that despite the efforts made in the education sector to give equal access to girls or to retain many of them in school for many years, there has been significant debate both in the media and public places on whether the policy re-admitting girls is achieving its intended purpose or its contributing to societies moral decay. Tjombonde (2003:49) points out that, "The Forum for African Women Educationalists in Namibia (FAWENA) has been advocating for the crafting and implementation of policies that address the issue of schoolgirl pregnancy." The scholar further found that some young mothers experienced problems in returning to school in that some teachers did not want to accept teenage mothers, and other teachers refused to take back teenage mothers whose infants died after a few weeks. Other than the difficult of returning as per provision of the teachers complain of the behaviour of these returning young mothers and lamented how difficult it has become to provide the education in line with the aims of Secondary School education and the general aims and objectives of education.

Furthermore, studies across Africa indicate that a cross section of society including parents, teachers, religious and civic leaders, traders and many other people have concerns that the policy to re-admit has not fully achieved its objectives in the different years that it has been in existence in countries like Kenya, Namibia, Ghana, Liberia and Zambia's 19 years no exception. The stakeholders to the reentry policy lament that there seems to be an aspect of promoting immorality, indiscipline and this may affect quality education delivery if this policy which is well-intended is not revisited to be made useful.

Close at home, many appreciate the policy especially in a Zambian society which has been characterised by inequality among men and women. The re-entry policy as a measure and recognition 
of the importance of addressing gender inequalities in national development and the need to narrow the gender gap in education. And quite a substantial number of girls in Zambian schools has benefited from the policy which was introduced on October 13, 1997 as (FAWEZA 2010) reports that it has scored a number of successes as some girls have gone back to school and successfully completed their secondary education, though some, older than the age they initially would have done so.

At the inception of the re-entry policy, in spite of, the United Nations Children's Fund and most women's non-government organizations being in full support of the policy, the church, the Zambia National Union of Teachers, some parents, teachers and some pupils, both boys and girls, opposed the move. This is evident from the finding of study by Zambia Association for Research and Development (ZARD) between October and December 1997 when it carried out an opinion poll on the re-admission of the pregnant child into school. The results confirmed the initial reactions. The church, parents, teachers and schoolboys were against the declaration fearing it will promote immorality.

In other studies carried out in Namibia indicate that the pupils welcomed the call by the policy that where a pregnancy occurred, the focus is on support rather than punishment. But in the various consultation meetings, some people, pupil's a part have favoured a punitive policy because they believe that a supportive approach 'condones' pregnancy amongst learners. But there is a difference between condoning learner pregnancy and addressing the problem of learner pregnancy. FAWENA in Tjombonde (2003) reported that the new policy acknowledges the reality in Namibia that teenagers and learners do give birth, and proposes new methods to deal with this situation. Thus, the study done on promoting girls' education through the re-entry policy for adolescent mothers revealed that reentry of young mothers into schools is still a major problem in many Namibian schools.

In another case of Namibia one pupil expressed on behalf of others how they view the policy when she asserted that, on the contrary, "the object of the policy is to punish young girls for making the grave mistake...", and that the result was to stigmatise such girls.

Caney (2005: 84) points out that, "various interventions have been undertaken to address the gender gaps in the education sector. Significant achievements have been scored through these initiatives towards improving girls' access, retention and performance. However, the gender disparities are still wide. It is clear however, that unless quicker and strategic action is taken to address these gaps, EFA goals are unlikely to be achieved." One strategy that is being proposed is to take successful interventions in order to ensure that a higher number of girls are reached. This has so far not been adequately undertaken. As a first step towards scaling up best practices, it is necessary to identify and document the most successful interventions in a way that can be taken up by education policy makers and other stakeholders.

To sum it up, this section was primarily concerned with answering the research objectives and research question. It has looked at on the development of education in Zambia and the re-entry policy. The review has shown an investment in girls' education is an investment in the family, community and nation, the centrality of women's contribution to national development as it improves overall quality of life for all. As such it is of significance to assess the effectiveness of re-entry policy which has brought about different viewpoints. Most methods used by scholars across the African continent on this topic are appreciated and adopted and the only gap identified is that the previous studies has less information on the behaviour of young mothers when they re-enter school after giving birth which this study may explore in ascertaining the effectiveness of the policy wholly.

\section{RESEARCH DESIGN}

A research design, according to Bryman (2008:698) is "a framework for the collection and analysis of data" which one employs in a research project or study. This research was designed in such a way that both qualitative and quantitative methods are used to collect data and analyse it. Under the qualitative method, the study utilized the skill of posing questions to respondents and based on the quality of answers the researchers will gather the data. The strength of this method enables the researcher to have a face to face interview with respondents and provides the researcher to have a chance to ask a 
follow up question and cross check the responses in order to come up with the truth. While quantitative method involves administering of questionnaires to respondents as individuals. Responses from the questionnaires were grouped into categories according to respondents' themes.

\section{Study Site}

The research was conducted in Western Province Township in particular. It covered four schools in this area which seems to be suitable for the researcher and the schools are Chunga, Diana Kaimba, Nelson Mandela and Matero Girls since, the schools are in the Urban and the area is highly populated. In choosing the research sites the researcher will rely on the principle that, Berg (2001:29) "the decision to use a particular research site is tied closely to obtaining access to an appropriate population of potential subjects"

\section{Target Population}

Lusaka City according ZDHS as at July, 2014 had a population of 1,980 million of which approximately 110, 311 are in Matero. In order to achieve these objectives it was necessary to get views from informants who the target group were academicians in the field of the re-entry policy and girls' education in Zambia. It included both female and male scholars, teachers, academicians and students/pupils of various ages. The study was conducted in four selected schools in Lusaka Province of Zambia. It included Senior Standard Officers at PEO and DEBS, Ministry of Education stakeholders, Teachers, pupils and parents.

\section{RESEARCH FINDINGS}

This section presents the findings of the study. It presents raw data as collected in the four selected schools in Lusaka's Matero Township so as to ascertain the effectiveness of the re-entry policy. A total of forty-one $(100 \%)$ questionnaires were prepared and distributed to the target group in a period of one month as follows; sixteen (16) to pupils, eight (8) to teachers, five (5) to parents and lastly, twelve (12) questionnaires were distributed among Administrators including Head Teachers, MOE officials at District and Provincial Offices and other key policy stakeholders. The researcher received back 39 questionnaires answered representing a total of 95\% as two (2) questionnaires were not returned. The data collected is presented in graphs to show the descriptive statistics and only the 39 questionnaires which were well answered are used in data presentation and analysis. The data collected through questionnaires and face to face interviews emerged into categories which were guided by the research objectives and questions. The findings in this chapter have been categorized based on the following research questions:
a. How effective is the re-entry policy in secondary schools in Lusaka urban?
b. How do pupils view the re-entry policy?
c. How do young mothers behave when they re-enter school in Lusaka urban?

\subsection{Effectiveness of the Re-Entry Policy}




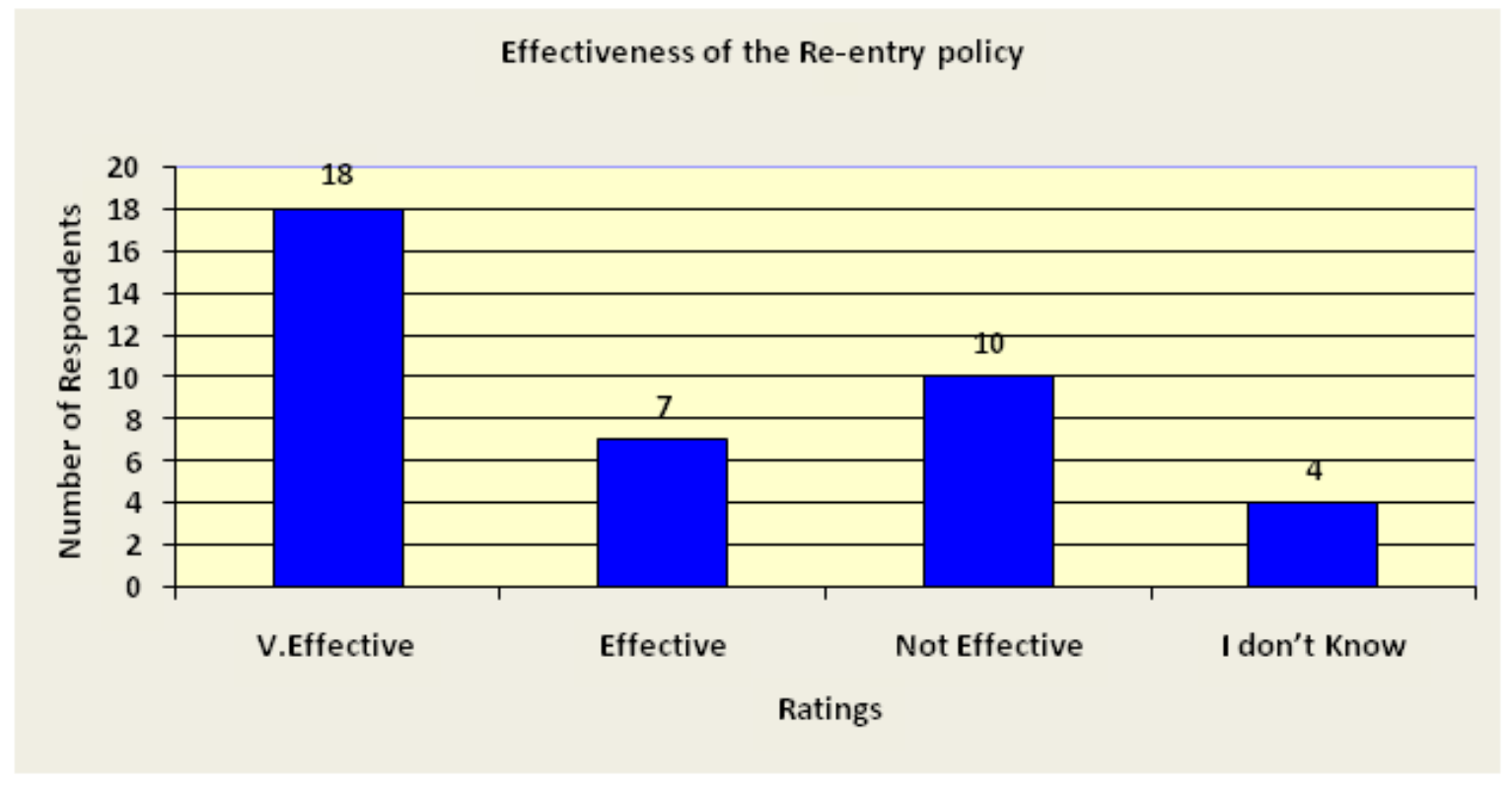

Figure1. Effectiveness of the Re-entry Policy

The effectiveness of the government intervention to ensure retention of girls in the education system such as re-entry policy was presented to the respondents to comment on. As indicated above, $46.2 \%$ showed high appreciation of the policy, while $17.9 \%$ felt the policy was just effective, while $25.7 \%$ felt the interventions are not influencing the girl child in Schools and finally 10.2\% however, admitted not having an idea on the effectiveness of MOE re-entry policy in Zambia.

One $(33.3 \%)$ of the three 'Standard Officer' from MOE Lusaka Provincial Education Office representing $33.3 \%$ when asked to comment on the effectiveness of re-try policy for girls who fall pregnant indicated that, in terms of retention the policy is effective in aspects of re-admission, progression, completion though there have been challenges in terms performance and behaviour with about $45 \%$ of the learners re-entering being among the pupils facing disciplinary issues in relation to the last three (3) years School Annual reports submitted.

Further, $10(25.7 \%)$ out of 39 respondents held that the policy is far from being effective especially in terms of moral development. 6 out of $8(75 \%)$ teachers and 2 out of $5(40 \%)$ parents and three $(60 \%)$ administrators who took part shared same thoughts and lamented that the policy is being abused by pupils. They argued that policy is not effective in achieving its intended goal and more so the aims of the Ministry of Education (1996) to pursue knowledge and skills, manifest excellence in performance and moral uprightness.

\subsubsection{Girls who Dropped from School on Maternity Leave}

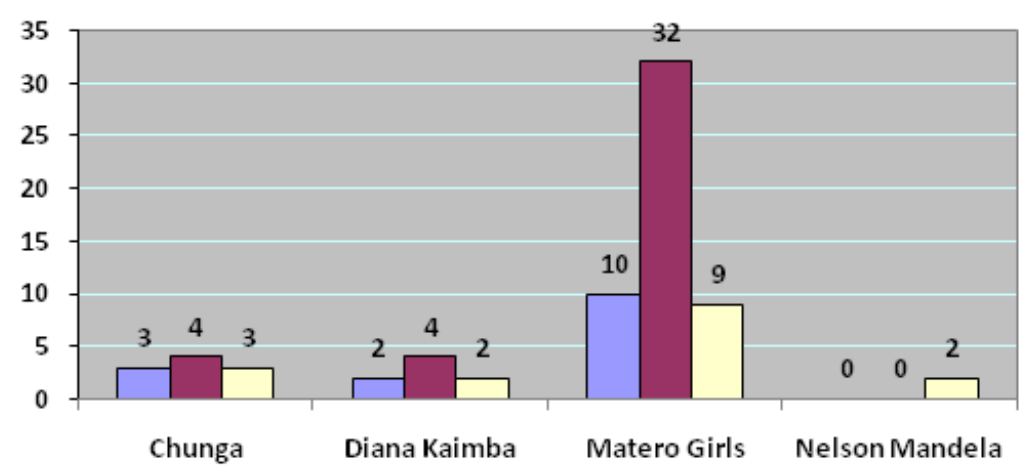

$\square 2013 \quad \square 2014 \quad \square 2015$

Figure2. Girls who dropped from school on maternity leave 
The information contained in the above figure 2 indicates that Matero Girls had the majority of the girls who got pregnant and went on maternity leave with 2014 having the highest with 32 sought leave. Nelson Mandela had 2 for 2015 and 0 for 2013 and 2014 respectively.

\subsubsection{Girls who Re-Entered School and Completed}

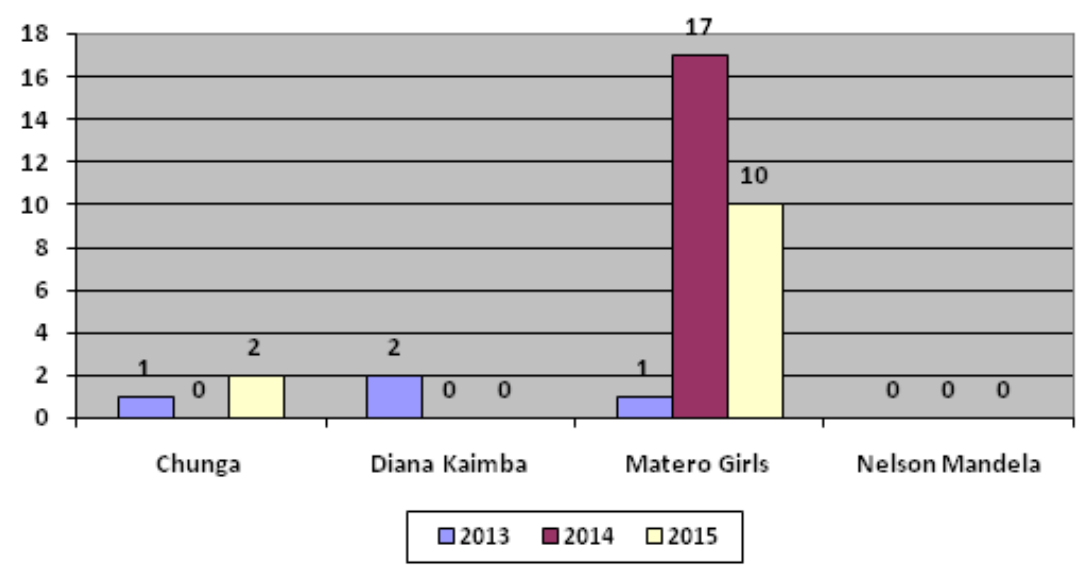

Figure3. Girls who re-entered school and completed

The above figure 3. contains information regarding the girls who went back to school and most of them completed. The findings from the four schools with exception of Matero with 17 and 10 for 2014 and 2015 respectively the closest schools had 2, 1 and mostly 0 girls returning and eventually completing their education.

The Stastician at Lusaka District Education Office and four Head Teachers (100\%) indicate that the $60 \%$ of the re-admitted learners changed schools as the policy gives room for them to choose whether to return to the same school or to change.

\subsection{Pupils View of the Re-Entry Policy}

Table1. Pupils view of the Re-entry policy

\begin{tabular}{|l|l|l|}
\hline Rating & Frequency & Percetange \% \\
\hline Good & 16 & 100 \\
\hline Average & 0 & 0 \\
\hline Below average & 0 & 0 \\
\hline Total & $\mathbf{1 6}$ & $\mathbf{1 0 0}$ \\
\hline
\end{tabular}

\subsection{Behaviour of Young Mothers when they Re-Enter}

Table2. Behaviour of young mothers when they re-enter

\begin{tabular}{|l|l|l|}
\hline Rating & Frequency & Percentage \\
\hline Good & 10 & 25.6 \\
\hline Normal & 11 & 28.2 \\
\hline Bad & 15 & 38.5 \\
\hline Not Sure & 3 & 7.7 \\
\hline
\end{tabular}

Table2 Shows the behaviour pattern of young mothers as cited by the respondents in the questionnaires, the bigger frequency is on somewhat bad though good and normal put together gets a bigger proportion.

- $\quad$ f 39 as shown in table 4.3 indicated that young mothers have some bad behaviour though good and normal put together reveals otherwise. When informants were asked to cite some of the disciplinary issues young mothers get involved when they re-enter school, the following alphabetically arranged emerged: absenteeism, Boy/Girl also teacher or married men sexual relationships, cheating in Internal Exams, defiance of authority, failure to do manual work, 
incomplete homework, laziness, rudeness to teachers, sleeping during class time truancy, and other disciplinary problems to do with fellow pupils

\section{DISCUSSION OF THE FINDINGS}

The right to education is a fundamental human right. Every individual irrespective of race, gender, nationality, ethnic or social origin, religion or political preference, age or disability, is entitled to equitable and successful completion of education. However at primary and secondary school level, most of the children who enrol do not realize their right to full basic education as most of them drop out. The rate at which students are dropping out of secondary school due to pregnancies is a dilemma and has become a serious problem for schools across Lusaka District. However, re- entry of pregnant girls continues to be a salient issue, though several schools across Zambia are grappling with the question of effectiveness of the re-entry policy. Qualitative and quantitative research methods were used to focus on the meaning that girl pupils make of their lives, their experiences, and their environment. A diverse group of forty-one participants from four secondary schools located in Lusaka's Matero Township made up the sample population specific to this study. The main research instruments were a self-administered questionnaire and face to face interview. These instruments generated valuable information and opinions from respondents from which the findings that are discussed here-in were based. According to the findings as presented in chapter four, the turnout of participants stands at $95 \%$.

\subsection{Effectiveness of the Re-Retry Policy}

In response to the above, evidence from the findings as shown in Figure 1 indicates that the re-entry policy of the Ministry of Education is effective (combining very effective $46.2 \%$ and effective makes $64.1 \%$ of the respondent) in retaining the pupils who become pregnant especially in terms of readmission, progression and the completion rate of pupils who become pregnant. Figure 4.1 in chapter four specify that there has been a great growth in the number of people, that is, teachers, pupils and parents who support the policy over the years and hold that it is working though it has gaps needing to be filled.

From the number of pupils under re-entry given in Figure 2 and Figure 3 shows that in the three years, (2013 and 2015) under review the retention rate is at $54.9 \%$. This finding mean the policy is effective in re-admitting girls in secondary schools and most of them completed.

Though due to insufficient records it was not possible to get exact numbers or what these beneficiaries to the policy are doing. However, a number of girls who benefited from the re-entry policy in years not covered by this study were reported to have been doing well in life after school although no precise figure was still given. It was reported that some were working as nurses, teachers while others were in other diverse as well as noble professions like one Lawyer.

In continuing to assess the effectiveness of the policy based on re-entering schools, progression and completion, it was brought to light with the challenges that came out very strongly include the fact that most girls do not go back to tell the school about their successes and failures. This is the reason why there was no specification as to the exact number of those who were nurses, teachers and those who were reported to be doing well in other sectors. The only update the school was getting was the girls' progression up to the tertiary level. As a result it is hard to conclude from the available statistics due to inaccessible records in some schools and at other Ministry of Education Levels.

On the other hand, the findings show that the policy is far from being effective especially in terms of excellence and moral uprightness as well as moral training. In this research, it was found that $25.7 \%$ of the respondents who rated the policy as ineffective based on the fact that it was not helping pupils to develop morally and keeping to societal norms which require one to be married to have a child. There is also a fear among some groups that the policy has led to increased cases of pregnancies. This assertion is held by $75 \%$ of teachers, $40 \%$ of parents and $60 \%$ administrators who took part in the study who collectively lamented that 
... the policy was developed in order to ensure that the pregnant learners may not lose out their time by waiting for delivery and breast feeding thereof. The policy has however overlooked the negative impact and influence which it is causing to the majority of teenagers (pregnancy). It is in fact encouraging more than discouraging. It is damaging more than repairing. It is simply sending a clear and loud message that teenage pregnancy has in fact become a moral practice in the society, so learners are free to engage themselves into sexual intercourse with their partners.

What came out strongly in line with figure 1 especially on the statistics on Matero Girls on girls who go on maternity leave is that, some learners misuse the policy by not taking care of themselves and keep themselves safe simply because they know even if they become pregnant, they will continue just like anybody else in the school. This thought backs the thought of the percentage that hold that the policy is ineffective as it lacks the elements that could make it deter others from becoming pregnant.

In addition, the above findings attest to the survey carried out by Faweza (2009) that a section of society who were against the policy in its current form held that it is contributing to society's moral decay and encourages immorality. Just like $33.3 \%$ of the proportion for parents believed that pregnant girls or young mothers returning and staying in school will encourage other girls to get pregnant as he made reference a second daughter who is on maternity leave at the time the study was being undertaken. For this percentage of parent pregnant girls are a bad example to the rest this collates with the observations Tjombonde (2003) expressed as the literature reviewed indicated.

Though a bigger percentage indicated that the re-entry was effective in terms of retention, the other proportion argued like a student teacher who told the media in April, 2014 that, "This re-entry policy is not working. And I am in support of the Catholic and other mission schools on this matter. Taking them back to conventional schools influences other school girls." The basis of most people who question the effectiveness is on moral training and deterrent aspect to others learners.

\subsection{Pupils View of the Re-entry policy}

There are so many benefits the country can get by educating the girl child and some among the many others include poverty reduction, significant reductions in infant mortality and morbidity, improvement in family nutrition and health, lowering of fertility rates, improved chances of children's education, and increased opportunities for income earning in both wage and non-wage sectors (Kelly 1999). Since women are the ones who are mainly involved in the welfare of the family, it becomes imperative that they are educated so that they can contribute to the reduction of poverty in the country. If women have little or no education it becomes tricky in that they would not understand issues that surround positive contribution for the benefit of all human beings. In view of this, $100 \%$ of pupils both boys and girls who took part in the study commended the re-entry policy wholly as shown in Table 2 and graph 2.

The study shows that $100 \%$ of the pupils talked to were in favour of the policy as it accords girls to complete their education despite the circumstances they find themselves. The pupils however, pointed out that being exposed to experience of being pregnant can have a lot of negative influence on other girls who may not take care of themselves and subsequently miss out on completing on time, with good moral standing in society as well as with exceptional good results.

$35 \%$ of the boys who participated in the study discussed that the policy was good and that the girls should be allowed to re-enter because they will have gained good experience never to repeat the mistake of getting pregnant. Further, the study revealed that the re-entry is supported because "most of the pregnancies are accidental and occur to youths who can become better people" stated a head boy teacher in one of the secondary schools.

Despite the $100 \%$ support, $31.7 \%$ of pupils felt otherwise and commented that being exposed to experience of being pregnant can have a lot of negative influence on other girls, the overall impression from both boys and girls, young mothers and none, signposted that the re-entry policy is a good policy as it accords girls to complete their education despite the circumstances they find themselves in.

And in response to the above, when teachers were asked to comment on the pupils perception of the policy, their was general consesus that pupils mostly were supportive of it and even to returnining 
mothers with few exceptions of stigma. Taking instance, $75 \%$ of the informant teachers commenting on pupil's view of the policy said, ...many appreciated the policy though as a guidance school teachers, know that absences have a serious impact on student success. Unfortunately, today's pregnant teens, who have already demonstrated some lack of judgment, also lack dedication and tenacity. Instead of viewing their baby as someone who will need a successful parent, they treat it like a toy, showing off ultrasounds and baby gifts. Any time they feel "uncomfortable" they stay home. They have no idea that life will just get harder and no one is teaching them that lesson sadly.

\section{Behaviour of Young Mothers when they Re-Enter}

The findings in chapter four revealed the respondents response to the question poised to them which was meant to help understand the behaviour of young mothers when they re-enter in the school environment as shown in table 2, were $38.5 \%$ which is the bigger proportion show that their behaviour is bad though good and normal put together is huge proportion stating otherwise.

The respondents cited the following as some of the behavioural aspects linked to young mothers;

Firstly, absenteeism and truancy were issues raised due to the fact that young mothers have additional responsibilities that their peers do not have. One respondent, an 'early mother', felt that the double responsibilities carried by these girls reduce their freedom compared to their fellow learners. She, however, expressed her feeling that at school she feels normal and free like any other ordinary learner but at home she has extra responsibilities as a mother. As she stated, "If my child is sick I have to be there and look after her or him."

In light of this, $75 \%$ of teachers supported the school Head Teachers (100\%) who pointed out apart from defiance of authority, failure to do manual work, late coming and rudeness to teachers, 'early mothers' do not have time to do their homework or even to study at home. As a result their homework is always incomplete or not done properly. They said that the only time they attend to schoolwork is during afternoon study if they happen to come. One teacher (12.5\%) said that, "They have many responsibilities and find it difficult to cope; consequently of this they are usually punished for the incomplete homework"

Continuously, another issue raised by the $53 \%$ of the respondents which comprised of pupils, teachers and administrators was the classroom situation concerning mothers. In this study they were concerned that these girls' concentration was impeded by their situation as some sleep during class time and this affected their performances in tests and examinations such that some resort to cheating. In addition, this group of respondents also remarked that young mothers are passive participants during lesson discussions.

The study also showed that young mothers had other disciplinary problems to do with fellow pupils. Josselson (2004) states that early childbearing among women below twenty years of age has been received as a social problem as it often leads to a premature end to many young women's educational careers in many Sub Saharan African countries. As such, the young mothers find themselves in disciplinary problems to do with fellow pupils as they are at times provoked. For instance, young mothers are called "ba solola" (prostitute), which means a prostitute, by their fellow learners. This does not sound good in local languages and it makes a person feel offended. Therefore, pupils should be educated on the need to respect their re-admitted friends and desist from mocking or making fun of them as they would be psychologically affected hence leading to poor performance in school.

Out of 39 respondents, $38.5 \%$ contends that young mothers generally have been framed as deviant students who were already performing poorly in school and therefore had low aspirations. Chigona and Chetty (2007) allude casting of pregnant school-girls as incapable" or poor students has had both short and long term implications on their educational experiences as well as those of young mothers learners.

Further, findings show that, besides some of the re-admitted girls tend to be arrogant and disrespectful towards teachers as they think that since they have babies they are at par with the educators. The results are that learning and teaching is negatively affected. However, this leads them to perform poorly in class as they feel they are in control of the school and no one can advise them. Further it has 
been stated that it is important for all stakeholders, especially parents to talk to the girl children reentering school in order to avoid a recurrence (Zambia daily mail, July 19, 2013).

\section{CONCLUSION AND RECOMMENDATIONS}

\subsection{Conclusion}

It can be said that although there is the re-entry policy for girls that fall pregnant as an intervention made by government and stakeholders to ensure retention and uplifting the standards of living among the girls and women, more remains to be done in terms of its effectiveness in the development of morals. The number of girls dropping out of school as a result of pregnancies and not making use of the re-entry policy is still high, threatening retention rates and the completion of studies by girlchildren at secondary level as shown in Figure 4.1.1 which shows a number of girls who went on maternity leave and Figure 4.2.1 of those who re-entered and completed. However, the findings show that the re-entry policy was effective in terms of retention of girls who fall pregnant especially in aspects of re-admission, progression, completion though there have been challenges in terms of performance, high achievement and behaviour.

The study has revealed that indiscipline by young mothers is detrimental to the effectiveness of the reentry policy as the results are that learning and teaching is negatively affected. Further, the study specified that it is important for all stakeholders, especially parents to talk to the girl children reentering school in order to avoid a recurrence.

From the findings of the research, it can be generalized that although the policy is effective in areas of re-admitting girls and ensuring their completion of education something need to be done in terms of moral uprightness and excellence among young mothers especially on the aspect of deterring others from becoming pregnant and behaving well in school when they re-enter. The study concluded that there was for the girls who fall pregnant to be re-admitted in adult educational institutions as their behaviour was attributed to the treatment from fellow pupils and teachers who were not prepared to handle such learners.

\section{The study makes the following recommendations}

i. Government should partner with other stakeholders such as Non-Governmental Organisations (NGOs) and communities to carry out awareness in the district which could effectively deal with misconceptions that the Re-entry policy promotes promiscuity among young girls by promoting the benefits of the policy on both the individual and improving ability of girls to progress to higher levels of education.

ii. The study recommends that counselling services be made available to girls to provide them with guidance and that these guidance and counselling sessions should be clearly indicated on the school time table where life matters should be addressed among others aspects.

iii. Schools should take the re-entry policy seriously and make sure that every girl child who falls pregnant re-enters.

iv. Ensure that students have a strong mutual relationship with at least one adult in the school. The education system needs to have well trained teachers who could be a focal point for pupils to talk to about personal problems. Most of respondents expressed on the need to do more to help students with problems outside of class.

v. The study recommends improved communication between parents and schools. The target group interviewed felt that one of the keys to keeping pupils in school and preventing pregnancies or when they occur to ensure girls benefited from re-entry policy was to have better communication between the parents and the school, and increasing parental involvement in their child's education.

vi. There is need to increase supervision in school and more classroom discipline. Many respondents felt their schools did not do enough to help girls make sense out of their daily living. The school environment should be one that reminds the learner that education is one of the most powerful tools to enable girls to avoid pregnancies and fulfil their potential.

vii. The study recommends teacher re-orientation and training so that they can handle issues of pregnancy and re-entry in school appropriately. 
viii. There is also need to empower vulnerable families through community initiatives in order for them to be able to take care of their children and avoid marrying-off their daughters so that they benefit from the re-entry policy by completing their study.

ix. Government should double its effort to ensure that more resources are allocated toward advocacy and awareness campaigns among the members of the community, teachers and pupils themselves so that there can be a reduction in pregnancy cases which will consequently impact positively on the girl child.

x. There is need to introduce more skills institutions for the girls who fall pregnant considering the society considered them adults so that the girls go to these institutions.

xi. Lastly, there is need by the government to increase the number of women in key positions so that girls in schools are motivated to work hard and stay in school.

\section{REFERENCES}

[1] Adetunde, I.A. \& Akensina, A.P. (2008) 'Factors affecting the standard of female education: A case study of senior secondary schools in the Kassena-Nankana district'. Journal of Social Sciences

[2] Berg, B. (2001). Qualitative Research Methods for the Social Sciences. London:

i. Allyn \& Bacon.

[3] Bryman, A. (2008). Social Research Methods (3rd Ed.). Oxford: OUP.

[4] Caney, S. (2005). Justice beyond Borders. Oxford: Oxford University Press.

[5] Carmody, B, (2004). The evolution of Education in Zambia. Lusaka:

i. Book world publishers Zambia.

[6] Gaisie, K., Cross, A.R. \& Nsemukila, G. (1993) Zambia Demographic and Health

a. Survey 1992. Lusaka: University of Zambia and CSO.

[7] FAWEZA, (2010), National Score Card on Zambia's Progress Towards Gender Equality in Education. Lusaka: FAWEZA.

[8] FAWEZA, (1996) Beyond Beijing: A summary of the global and Africa region platforms

i. for action with a focus on education. $4^{\text {th }}$ World Conference on Education.

[9] Gay, L. R; (1992). Educational research: Competences for analysis and application.

a. Ohio: Charles E. Merrill Publishing Company.

[10] Gosh, B. N, (2008). Scientific Method and Social Research. New Delhi: Sterling

i. Publishers Ltd.

[11] Kelly, M. J, (1999) Girls Education, A situation Analysis at the provincial Centre of

i. Girl Child Education in Zambia. Lusaka: Ministry of Education.

[12] Marshall, C. \& Rossman, G.B. (2006). Designing qualitative, research. $\left(4^{\text {th }}\right.$ Ed.) London:

i. Sage Publications.

[13] MOE (1996): Educating Our Future. Government Printers, Lusaka.

[14] Tjombonde, V. (2002). Promoting girls' education through re-entry policy for adolescent

i. mothers: A case study to provide an in-depth review of the implementation

ii. of the Teenage Pregnancy Policy in Namibian schools. Windhoek:

iii. Forum for African Women Educationalists in Namibia.

Citation: Dr. Martin Banda \& Mable Sitali Nowanga. "The Efficacy of Re-Entry Policy and Its Implications on the Zambian Education System" International Journal of Humanities Social Sciences and Education (IJHSSE), vol 4, no. 12, 2017, pp. 83-95. doi: http://dx.doi.org/10.20431/2349-0381.0412011.

Copyright: () 2017 Authors. This is an open-access article distributed under the terms of the Creative Commons Attribution License, which permits unrestricted use, distribution, and reproduction in any medium, provided the original author and source are credited. 